\title{
Single-Step Heat Treatment for the Restoration of the Mechanical Properties of Cold-Strained Mining Support Steel 31Mn4
}

\author{
Gorazd Lojen $1{ }^{*}$ - Janez Mayer ${ }^{2}$ - Tonica Bončina ${ }^{1}$ - Franc Zupanič ${ }^{1}$ \\ ${ }^{1}$ University of Maribor, Faculty of Mechanical Engineering, Slovenia \\ 2Premogovnik Velenje, d. d., Slovenia
}

The steel 31Mn4+QT630 is used frequently for mining support arches. The supports are cold strained, first during service, and again by rerolling prior to reinstallation, which results in strain hardening and a loss of ductility. Consequently, many of the rerolled arch-segments are not suitable for reinstallation because their mechanical properties are inadequate. The objective of this work was to assess the feasibility of restoration of the required mechanical properties by means of a cost-efficient single step heat treatment. Specimens were cold deformed to different degrees in the range $0 \%$ to $45 \%$ to establish the relation between the degree of cold deformation and the hardness. Differently strain hardened specimens were subjected to subcritical annealing at temperatures $450^{\circ} \mathrm{C}$ to $700^{\circ} \mathrm{C}$ in the duration $0.5 \mathrm{~h}$ to $8 \mathrm{~h}$ to determine a suitable time-temperature combinations. Microstructures and mechanical properties were investigated of as-received, cold strained and recrystallized specimens. Tests performed were optical microscopy, scanning electron microscopy, tensile tests, hardness measurements and Charpy impact tests. Elongation at break of the as-received material was below the requirements of the applicable standard, and its microstructure contained significant fractions of pre-eutectoid ferrite and pearlite. Upon cold straining, hardness increased by approximately $2 \mathrm{HV}$ per $1 \%$ of strain. After one-hour recrystallization at $600{ }^{\circ} \mathrm{C}$ to $620^{\circ} \mathrm{C}$, the microstructure consisted of a ferritic matrix containing evenly dispersed globular carbide particles. The original ductility was restored, while the elongation, yield strength, and hardness were higher than in the as-received condition. These results confirmed that it is feasible to restore the original mechanical properties of heavily strained profiles with an adequate single-step heat treatment. Furthermore, they indicated that it should be possible to recover the required properties of inhomogeneously strained material with the same set of well optimized heat treatment parameters. Consequently, it should be possible to increase the reuse rate and to decrease the costs for new support arches significantly.

Keywords: microstructure, strain hardening, mechanical properties, recrystallization, steel 31Mn4, steel 1.0520, steel mining supports

\section{Highlights}

- The possibilities were assessed for restoration of the required mechanical properties of damaged (cold strained) mining support steel 31Mn4+QT630.

- The relation between hardness and cold deformation in the range from $0 \%$ to $45 \%$ of cold deformation was established experimentally to be approximately linear, 2 HV per $1 \%$ of cold deformation.

- Restoration of the required combination of yield strength, tensile strength, elongation, hardness and impact toughness was possible by an adequate single step heat treatment (solely by recrystallization). The optimum combination of time and temperature was established to be about $1 \mathrm{~h}$ at $600^{\circ} \mathrm{C}$ to $620^{\circ} \mathrm{C}$.

- Cold plastic deformation and subsequent recrystallization improved the homogeneity and ductility of the steel compared to new profiles in as-delivered condition QT630.

- By the implementation of a simple and inexpensive treatment, consisting of determination of the degree of cold strain and a corresponding single-step heat treatment, it should be possible to increase the reuse rate of mining support arch segments, and, thereby, to decrease the expenses and the environmental impact of mining.

\section{INTRODUCTION}

In underground mines, dynamically capable ground support systems are one of the most reliable options [1]. A steel arch yielding support of roadways is a widely used support structure in European mines [2] and worldwide. For example, in German coal mines, $65 \%$ of roadways are supported by yieldable steel arches and the percentage is still growing [3]. Not only the design of the arch [4], but also the shape of the profiles` cross-sections influence the load capacity of the support.

With respect to bearing capacity, the arches built of profiles with open cross-sections like U and V-shaped cross-sections are inferior to those made of concrete filled tubes [5]. However, the significant advantage of yielding steel-arch supports made of V-shaped profiles is the yielding capacity of connections between the segments. The most visible manifestation of strata pressure is the vertical convergence of roadways [6]. When the ground load on the support increases, the sliding of the arch segments over each other facilitates the arch closure, i.e. diminishing the tunnel's radius. This leads to a decrease in the pressure exerted on the arch by the ground, reaching an equilibrium state, overload is prevented and the arch continues to provide support despite significant roadway deformations [7]. Gradual 
stress relaxation (i.e. smooth yielding) decreases the risk of rock burst [8].

To withstand the sufficient clamping forces and to enable smooth yielding, the material must exhibit sufficient strength and hardness. Because the yielding is inevitably accompanied by plastic deformation, adequate ductility is also required to ensure a sufficient yielding capacity. Excessively deformed profiles must be replaced, after the yielding capacity of the connections is fully exploited, or in the case of sudden, heavy overloads.

To maintain the production in the underground mines, a huge amount of steel supports must be installed every year. Thus, the new steel supports not only represent a considerable expense, but also have a great impact on the environment. For example, a lifecycle assessment for coal mining operations in Poland revealed that the production of steel supports for underground mining ranks fourth among coal mining related factors that affect greenhouse gas emissions [9]. Therefore, reducing steel consumption by repairing and reusing damaged steel arches not only lowers the costs, but also improves the environmental balance of mining significantly. Currently, about $3 \times 10^{6} \mathrm{~kg}$ of steel arch segments are discarded every year in the Coal mine in Velenje. The responsible Department estimates that approximately $1 / 3$ of them could be reused if a reliable and inexpensive heat treatment would be available.

The uninstalled supports are divided into two groups. The kinked segments are discarded, while the more uniformly deformed arch-segments can be repaired (i.e. rerolled). However, repair makes sense only if, after re-rolling, the ductility is not too low. Namely, upon re-rolling the total degree of plastic deformation approximately doubles, whereby the ductility decreases. Conveniently, the degree of plastic deformation of rerolled segments is quite uniform along their length. Therefore, the restoration of required mechanical properties should be possible solely by adequate recrystallization annealing, which is much cheaper and less time consuming than new austenitization, quench hardening and tempering. Nevertheless, no reports on attempts to repair of the profiles and no reports on heat treatments of quenched and tempered and subsequently cold strained steels could be found in the literature.

Many research groups investigated recrystallization, subcritical, intercritical and/or supercritical annealing of other steels. Zhao and Chen [10] researched a two-stage heat treatment (intercritical and subsequent subcritical annealing) of cold rolled low alloy steel $20 \mathrm{CrMnTi}$ in order to obtain fine pearlite and ferrite grains. Optimization of annealing parameters resulted in finer grains, a more uniform distribution of ferrite and pearlite and in an increase of plasticity. Al-Qawabah et al. [11] researched the effect of normalization temperatures in the range 820 ${ }^{\circ} \mathrm{C}$ to $940{ }^{\circ} \mathrm{C}$ on the microstructure, microhardness, mechanical behavior and impact toughness of grade 45 low carbon steel. With increasing austenitization temperature, the grain size and the plasticity increased constantly, while the impact toughness and microhardness increased only up to $900{ }^{\circ} \mathrm{C}$ and $860{ }^{\circ} \mathrm{C}$, respectively. Kubendran Amos et al. [12] studied the spheroidization of pearlite during subcritical annealing. The effective spheroidization mechanism depended on the initial aspect ratio of a cementite plate. Ji et al. [13] investigated the influences of different temperatures of subcritical annealing on the spheroidization ratio and mechanical properties of medium carbon steel SCM435. With increasing the annealing temperature up to $720{ }^{\circ} \mathrm{C}$, the spheroidization ratio of carbides and ductility increased, while the tensile strength decreased. After annealing in the temperature range $680{ }^{\circ} \mathrm{C}$ to 720 ${ }^{\circ} \mathrm{C}$, mechanical properties were comparable to those obtained with intercritical annealing. Hernandez-Silva et al. [14] studied the spheroidization of cementite in AISI 1541 carbon steel by means of subcritical and intercritical annealing. Spheroidization was faster if prior to subcritical annealing, the steel was cold deformed or intercritically annealed. Bhattacharya et al. [15] studied subcritical annealing of lowcarbon microalloyed steel after different sequences of hot rolling. An ultrafine grain microstructure, obtained by $80 \%$ warm deformation followed by intercritical annealing at $800{ }^{\circ} \mathrm{C}$ for $5 \mathrm{~min}$ and water quenching, resulted in the optimum combination of strength and ductility. It was not reporterd how the optimum combination was determined. Mugas et al. [16] investigated the effects of subcritical annealing followed by oil and water quenching on $\mathrm{Ck} 55$ carbon steel. They found out that conventional hardening consisting of austenitization, quenching and tempering, could be replaced by subcritical annealing followed by quenching. Perez [17] explored the impact of different types of annealing treatments on the softening and subsequent work hardening behavior of a martensitic stainless steel. Subcritical annealing resulted in significant softening, while the ductility and work-hardening behavior were not strongly affected. Austenitization followed by slow cooling had no significant influence on hardness and strength. The influences of heating rate during subcritical annealing (recrystallization) of severely deformed 
low carbon steel were explored by Ghiabakloo and Kazeminezhad [18]. Fully recrystallized samples, heated rapidly to $600{ }^{\circ} \mathrm{C}$ in a metallic bath, exhibited higher hardness and strength than conventionally recrystallized samples. Yang and $\mathrm{Lu}$ [19] reported optimization of intercritical annealing parameters for cold-drawn SCM435 steel wires in order to obtain the optimum mechanical properties of the wire. The degree of cold deformation was not reported, while the best obtainable combination of mechanical properties was found to be the ensile strength $527.1 \mathrm{MPa}$, hardness 76.2 $\mathrm{HRB}$ and ductility 0.437. Yang and $\mathrm{Lu}$ [20] and [21] also studied the effects of the type of the protective atmosphere on subcritical and intercritical annealing of SCM435 alloy steel wires. For the improvement of plasticity, a hydrogen atmosphere was found to be more suitable than nitrogen, and intercritical annealing more efficient than subcritical annealing. Joo et al. [22] studied the influence of the shape of the matrix for cold drawing prior to annealing at $705{ }^{\circ} \mathrm{C}$ on ductility and spheroidization of carbides in a medium carbon steel for production of wires. Drawing through a non-circular matrix influenced the ductility and spheroidization of cementite beneficially. Influences of the presence of $\mathrm{Mn}, \mathrm{V}$ and Ti on kinetics and the interaction between recrystallization and precipitation during subcritical annealing of cold-rolled low-carbon steels were investigated by Kapoor et al. [23]. Recrystallization progressed faster in samples containing less $\mathrm{Mn}, \mathrm{V}$ and Ti. Min and Ha [24] studied the spheroidization of pearlite and mechanical properties of pearlitic steel after cold rolling for $20 \%$ to $40 \%$ and subsequent subcritical annealing at $600{ }^{\circ} \mathrm{C}$ and $720{ }^{\circ} \mathrm{C}$ for $0.1 \mathrm{~h}$ to $32 \mathrm{~h}$. Ductility decreased with increasing cold reduction. Elongation increased dramatically with prolongation of spheroidization annealing. Yang and Liu [25] attempted optimization of the spheroidization of pearlite at $695{ }^{\circ} \mathrm{C}$ to $705^{\circ} \mathrm{C}$ in AISI 1022 low carbon steel after cold deformation, in order to improve the cold forging properties The temperature and duration of annealing were recognized as the most significant parameters. The optimum values were $705^{\circ} \mathrm{C}$ and $8 \mathrm{~h}$.

U-shaped profiles and steel $31 \mathrm{Mn} 4$ according to DIN 21530-3:2016-09 [26] are used widely for yielding steel arch supports in numerous underground mines all over the world, and the use of $31 \mathrm{Mn} 4$ steel is still increasing [27]. However, only a few publications could be found that reported on U-shaped profiles for steel arches, and/or on 31Mn4 steel. Plesea and Radu [28] studied cold bending of U-shaped mining support profiles, residual stress and the occurrence of cracks by means of analytical and numerical analysis. They proved that, already during manufacturing of arch segments by cold bending, very high residual stress can be introduced and cracks can even occur. However, the profiles were not made of $31 \mathrm{Mn} 4$ steel, profiles were not quenched and tempered (QT) before bending and the research was focused on production of new arch segments. Radu et al. [29] and Majcherczyk and Malkowski [27] studied the mechanical performance of different support systems and different u-shaped profiles for steel arch supports. Work hardening and heat treatments were not addressed. Kilerci and Culha [30] studied hot forging of $31 \mathrm{Mn} 4$. With an increasing number of forging stages, occurrence of cracks and forging forces decreased. Aritan and Can [31] focused on corrosion of $31 \mathrm{Mn} 4$ steel arch supports. They compared corrosion rates in underground mine water from a certain mine, in bore water, and in pure water. The corrosion rate was the highest in the mine water. Janas et al. [32] analyzed the load-carrying capacity of steel arch supports made of $31 \mathrm{Mn} 4$, and developed software for calculation of load-bearing capacity of profiles TH 29 and TH 34 made of 31Mn4 steel.

No data regarding the relationship between hardness and deformation or the properties after recrystallization treatment of strain hardened 31Mn4 steel can be found in open literature neither for normalized nor for quenched and tempered condition. Therefore, the goal of our research was to find a simple, fast, reliable and inexpensive way to determine the actual condition of cold strained segments and to recover the ductility of excessively strain hardened segments.

\section{METHODS}

Cuboid samples were machined from new (unused) steel arch segments. The samples were compressed to different degrees, and their hardness was measured in order to determine the relationship between the hardness and the degree of cold deformation. Subsequently, the samples were recrystallized using different time-temperature combinations to establish a suitable combination for the restoration of original mechanical properties. Tensile tests and Charpy impact tests were performed to verify the suitability of the heat treatment. Evolution of microstructure upon strain hardening and subsequent heat treatment and fracture surfaces were investigated with a high resolution scanning electron microscope. 


\section{EXPERIMENTAL}

Samples were obtained from new profiles TH 29 made of steel $31 \mathrm{Mn} 4$, delivered in quenched and tempered condition +QT630, which is included in the standard DIN 21530-3:2016-09. The chemical composition of the analyzed profile was found to be within the specified range, Table 1. An ARL 3460 optical emission spectrometer was used for the chemical analysis.

Table 1. Chemical composition of steel $31 \mathrm{Mn} 4$ to DIN 215303:2016-09 and analyzed composition

\begin{tabular}{lcc}
\hline Element & DIN 21530-3:2016-09 [wt. \%] & Analyzed [wt. \%] \\
\hline $\mathrm{C}$ & 0.28 to 0.36 & 0.36 \\
\hline $\mathrm{Si}$ & 0.20 to 0.50 & 0.36 \\
\hline $\mathrm{Mn}$ & 0.80 to 1.10 & 0.91 \\
\hline $\mathrm{P}$ & $\leq 0.035$ & 0.016 \\
\hline $\mathrm{S}$ & $\leq 0.035$ & 0.007 \\
\hline $\mathrm{Al}$ & $\leq 0.020$ & - \\
\hline $\mathrm{Cu}$ & $\leq 0.35$ & - \\
\hline $\mathrm{Ni}$ & & 0.02 \\
\hline $\mathrm{Cr}$ & & 0.05 \\
\hline
\end{tabular}

Metallographic examinations, hardness tests, tensile tests and Charpy impact toughness tests followed. Examinations and tests were done with specimens in different conditions: As-received (+QT630), strain hardened by compression, and in recrystallized condition.

Classic metallographic preparation was applied, consisting of grinding, polishing and etching with the nital/picral, ratio 10:1. The microstructures were examined with a scanning electron microscope FEI Sirion 400 NC, equipped with the EDX system Oxford INCA 350. Vickers hardness HV 30 was measured with a VPM Leipzig HPO 250 hardness tester.

The shaded area in the Fig. 1 indicates the position of specimens in the TH 29 profile. The longitudinal axis of specimens was parallel to the profiles' longitudinal axis.

Specimens $15 \mathrm{~mm} \times 15 \mathrm{~mm} \times 30 \mathrm{~mm}$ were used to determine the relation between the degree of cold plastic deformation and hardness. The cuboids were compressed in the longitudinal direction with a universal hydraulic testing machine VPM Leipzig EDZ 100. Preliminary tests confirmed that the highest increase of hardness occurred in the area around the body center of a compressed specimen and that the results are practically independent of the sectionorientation. Therefore, the hardness was measured in this area. Afterwards, the same specimens were used to assert the appropriate time and temperature of recrystallization.

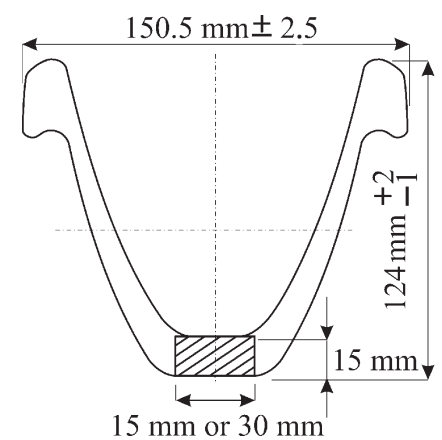

Fig. 1. Cross-section of the profile TH 29. The shaded surface at the bottom shows the position of specimens

Cuboids $15 \mathrm{~mm} \times 30 \mathrm{~mm} \times 90 \mathrm{~mm}$ and $15 \mathrm{~mm}$ $\times 30 \mathrm{~mm} \times 60 \mathrm{~mm}$ were used for the tensile tests and Charpy impact toughness tests, respectively. Some were left in as-received condition, while others were compressed in the transverse direction with a hydraulic compression testing machine VPM Leipzig ZDM 300. Some compressed specimens remained in the cold strained condition, while the rest were recrystallized. Adequate test pieces were machined from specimens in all three conditions: Short standard B-type specimens according to DIN 50125 [33] for tensile tests, and ISO-V-notch specimens according to EN ISO 148-1 [34] Charpy impact toughness tests. A Messphysik Beta 300 machine was used for tensile tests, and a $300 \mathrm{~J}$ notch impact tester PSW 300 from VPM Leipzig for the Charpy tests. The Vickers hardness of V-notch specimens was measured additionally.

\section{RESULTS AND DISCUSSION}

\subsection{Relationship between Deformation and Hardness}

The $15 \mathrm{~mm} \times 15 \mathrm{~mm} \times 30 \mathrm{~mm}$ cuboids were compressed in the longitudinal direction to different degrees of final deformation to investigate the relationship between the degree of cold deformation and hardness. Hardness was measured in the area of the highest deformation, on the cross-section through the body center. The results are presented in Fig. 2. The relationship between the degree of deformation and hardness was almost linear.

Assuming a linear relationship, shown by the calculated dotted trend line, the hardness increased by 2.03 Vickers units per $1 \%$ cold deformation, Eq. (1):

$$
H V=H V_{0}+2.03 \times \varepsilon .
$$


In the Eq. (1), $H V$ represents the final hardness after cold deformation, $H V_{0}$ the initial hardness before cold deformation, and $\varepsilon$ the degree of cold deformation in percentage.

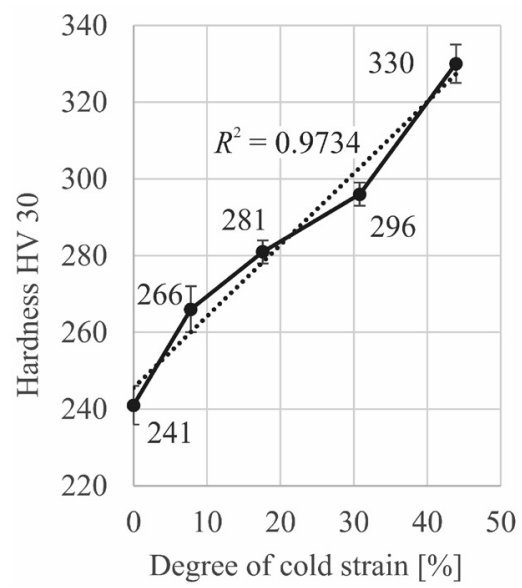

Fig. 2. Influence of cold straining on the hardness of $31 \mathrm{Mn} 4+Q T 630$ steel. The exact degrees of compressive cold deformation were $0 \%, 7.8 \%, 17.6 \%, 30.8 \%$ and $43.9 \%$

Opposite to our specimens, steel arches in the mines are deformed by bending. Therefore, the maximum plastic deformation always occurs on the surface of the profile, where the hardness can be measured easily and quickly with portable hardness testers. Hence, Eq. (1) can be used for determining the degree of cold plastic deformation of profiles.

\subsection{Recrystallization Parameters}

In the first step, two groups of specimens, cold strained for $10 \%$ and $45 \%$, were annealed for $1 \mathrm{~h}$ at different temperatures. The specimens were inserted into a preheated furnace and time was measured from the moment when the specimens reached the set temperature. The necessary time for heating up was determined experimentally. The test pieces were used with a drill hole reaching into the body center. One thermocouple was placed into the drill hole, and the other was in contact with the surface. For both thermocouples, the necessary time to reach the pre-set furnace temperature were measured; $t_{1}$ for the surface and $t_{2}$ for the body center. The delay of the body center $\Delta t$ was determined from their difference. Because the test pieces with a drill hole were inconvenient for other experiments, later, only the surface temperature was measured. After $t_{1}+\Delta t$, we started to measure the soaking time.

It was found that a hardness of about $250 \mathrm{HV}$ can be obtained at approximately $600{ }^{\circ} \mathrm{C}$, Fig. 3a. The less strained specimens softened more slowly. Hence, the risk that, after recrystallization, the less strained sections of profiles would be too soft, while more heavily strained areas would regain the required mechanical properties, is low.

In the second step, a third group of specimens, all of them being cold strained for $45 \%$, was annealed at various temperatures for up to 8 hours to assess the influence of the annealing time, Fig. $3 \mathrm{~b}$. Again, the optimum temperature was found to be around $600{ }^{\circ} \mathrm{C}$. At $600{ }^{\circ} \mathrm{C}$, the hardness reached $259 \mathrm{HV} 30$ in $0.5 \mathrm{~h}$, $254 \mathrm{HV} 30$ in 1 hour and $242 \mathrm{HV} 30$ in 2 hours. It was evident that temperatures below $600{ }^{\circ} \mathrm{C}$ were too low to obtain hardness near $250 \mathrm{HV} 30$ in a reasonable time. On the other hand, temperatures of $650{ }^{\circ} \mathrm{C}$ and above were too high. At $650{ }^{\circ} \mathrm{C}$, the hardness reached

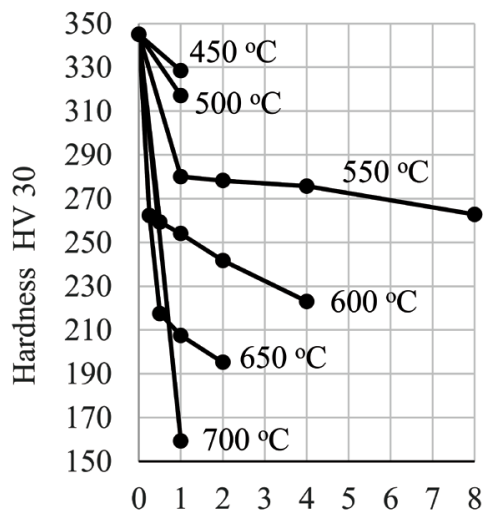

b) Annealing time $[\mathrm{h}]$

Fig. 3. Hardness of 31Mn4+QT630; a) cold strained for $10 \%$ and $45 \%$ and annealed for $1 \mathrm{~h}$ at different temperatures, and b) $45 \%$ cold strained and annealed at different temperatures for up to 8 hours 
250 HV 30 in about 15 minutes. Such short times are unsuitable for the industrial environment, because the process is too difficult to control with sufficient accuracy.

\subsection{Mechanical Properties}

The results of mechanical tests are summarized in Table 2. The minimum mechanical properties for 31Mn4+QT630 steel according to DIN 21530-3:201609 are listed at the bottom of the Table.

\subsubsection{Tensile Properties}

The tensile tests revealed that tensile strength and yield strength of as-received specimens met the requirements of DIN 21530-3, while elongation of one specimen did not reach the required $16 \%$. Like the low hardness, the insufficient elongations can also be attributed to the inhomogeneous microstructure, which is discussed in Section 3.4.1 Microstructures. As expected, tensile strength increased strongly due to strain hardening, while elongation at break decreased.

All recrystallized specimens had yield points far above the requirements of the Standard. One of them, the one strained for $33 \%$ and recrystallized at 620 ${ }^{\circ} \mathrm{C}$, exhibited insufficient tensile strength. The tensile strengths of the recrystallized specimens were lower than in the as-received condition, while their yield points were, on average, significantly higher. The elongations at break of the recrystallized specimens were, on average, also higher than in the as-received condition. Only one of them, strained for $45 \%$ and recrystallized at $600{ }^{\circ} \mathrm{C}$, did not quite reach the required $16 \%$ elongation.

These test results imply that it is not easy to find the right balance between tensile strength and elongation. Moreover, the recrystallization temperature should be chosen carefully with respect to the degree of previous cold plastic deformation.

In addition, it was observed that the characteristics of the yield point changed upon recrystallization. Nonstrained specimens and strained but not recrystallized specimens exhibited an offset yield point $R_{\mathrm{p} 02}$, typical for hardened and cold worked steels. Recrystallized specimens exhibited a higher yield point $R_{\mathrm{eh}}$ and lower yield point $R_{\mathrm{el}}$, which is characteristic for mild steels. The appearance of $R_{\mathrm{eh}}$ and $R_{\mathrm{el}}$ on the one hand, and $R_{\text {eh }}$ being higher than $R_{\mathrm{m}}$ on the other hand, can be attributed to the diffusion and piling of foreign atoms around the dislocations in the iron lattice [35] during the recrystallization treatment, which hindered the start of the dislocation glide during the tensile test.

\subsubsection{Hardness}

The hardness of the ISO-V and the tensile test specimens in as-received condition was not measured, because the hardness in this condition was already determined with other specimens, and was about 240 HV 30 on average, Table 2. After recrystallization, the average hardness was higher than in the as-received

Table 2. Mechanical properties of $31 \mathrm{Mn} 4+Q T 630$ steel in as-received, cold strained, and recrystallized condition, and minimum requirements according to DIN 21530-3:2016-09

\begin{tabular}{cccccccccc}
\hline$\varepsilon[\%]$ & $T_{\mathrm{r}}\left[{ }^{\circ} \mathrm{C}\right]$ & $t_{\mathrm{r}}[\mathrm{h}]$ & $R_{\mathrm{eh}}[\mathrm{MPa}]$ & $R_{\mathrm{el}}[\mathrm{MPa}]$ & $R_{\mathrm{p} 02}[\mathrm{MPa}]$ & $R_{\mathrm{m}}[\mathrm{MPa}]$ & $A_{5}[\%]$ & $A v[\mathrm{~J}]$ & $H V 30$ \\
\hline 0 & - & - & - & - & 727 & 868 & 16.9 & 100 a) & 241 \\
\hline 13 & - & - & - & - & - & - & - & 99 a) & 296 \\
\hline 30 & - & - & - & - & 1067 & 1180 & 6.8 & $42 \mathrm{a})$ & 296 \\
\hline 45 & - & - & - & - & 1132 & 1202 & 5.3 & 40 a) & 339 \\
\hline 13 & 600 & 1 & - & - & - & - & - & 117 a) & 246 \\
\hline 28 & 600 & 1 & 829 & 800 & - & 836 & 19.9 & - & - \\
\hline 29 & 600 & 1 & 867 & 804 & - & 849 & 16.3 & - & - \\
\hline 30 & 600 & 1 & 878 & 793 & - & 834 & 17.7 & 91 a) & 266 \\
\hline 45 & 600 & 1 & 859 & 830 & - & 851 & 14.6 & 99 a) & 285 \\
\hline 31 & 620 & 1 & 844 & 787 & - & 818 & 20.9 & - & - \\
\hline 33 & 620 & 1 & 766 & 699 & - & 715 & 16.4 & - & - \\
\hline & DIN 21530, QT630 & $\geq 630$ & - & - & $\geq 790$ & $\geq 16$ & $\geq 70 / 75$ b) & - \\
\hline
\end{tabular}

$\varepsilon=$ cold strain [\%]; $T_{\mathrm{r}}=$ recrystallization temperature $\left[{ }^{\circ} \mathrm{C}\right] ; t_{\mathrm{r}}=$ recrystallization time $[\mathrm{h}] ; R_{\mathrm{eh}}=$ upper yield point; $R_{\mathrm{el}}=$ lower yield point, $R_{\mathrm{p} 02}=$ offset yield point (at $0.2 \%$ of plastic deformation); $R_{\mathrm{m}}=$ Tensile strength, $A_{5}=$ elongation after fracture, obtained with test pieces having a length:diameter ratio 5:1; $A v=$ impact energy absorbed in the Charpy test; $H V 30=$ Vickers hardness, measured with a load of $30 \mathrm{~kg}$; a) ISO-V specimens at room temperature; b) DVM specimens, single specimen/average of 3 specimens at room temperature 
condition. Only one specimen, strained for $13 \%$ and recrystallized at $600{ }^{\circ} \mathrm{C}$, exhibited a hardness lower than $250 \mathrm{HV}$. Nevertheless, even this specimen was harder than the majority of specimens in the asreceived condition.

\subsubsection{Impact Toughness}

For the average of three specimens, the standard DIN 21530-3:2016-09 specifies the threshold value of $75 \mathrm{~J}$ DVM. However, ISO-V specimens are more common than DVM specimens. Therefore, the ISO-V form was selected for impact toughness tests in our research. A comparison of DVM and ISO-V values [36] shows that $63 \mathrm{~J}$ DVM equals $63 \mathrm{~J}$ ISO-V. Above $63 \mathrm{~J}$, the ISOV-values are higher than DVM-values: $72 \mathrm{~J}$ DVM corresponds to $75 \mathrm{~J}$ ISO-V, and $77 \mathrm{~J}$ DVM corresponds to $82 \mathrm{~J}$ ISO-V. Accordingly, the threshold value for ISO-V specimens would be around $80 \mathrm{~J}$. In this regard, the impact toughness of recrystallized specimens was always above the required minimum value, and even a moderately cold strained specimen (13\%) exhibited impact toughness higher than required. As expected, the impact toughness of heavily strained (30\% and 45 $\%)$ and not recrystallized specimens was insufficient.

\subsection{Microstructures and Fracture Surfaces}

Microstructures and fracture surfaces of specimens were examined in all three conditions. However, for the purposes of this examination, the most relevant comparisons are between the as-received and the recrystallized conditions. Therefore, only photographs of these two conditions are presented below, while the cold strained condition is only described shortly in the text.

\subsubsection{Microstructures}

Characteristic microstructures of as-received, cold deformed and recrystallized material are presented in Fig. 4. The SEM image of the as-received material, Fig. 4a, reveals that the microstructure contained ferritic grains (dark), relatively coarse lamellar areas, and areas containing much finer lamellar and globular carbides. The coarser lamellar areas were pearlite. The presence of proeutectoid ferritic grains and pearlite indicates that the steel was not quenched properly - the cooling rate was too low. The presence of ferrite explains the low hardness of the as-received material, and the inhomogeneity of the microstructure contributed to the relatively low elongations. Because the material was tempered after quenching, the areas containing finer carbides could be bainite and/or tempered martensite, as well as partially spheroidized fine pearlite.
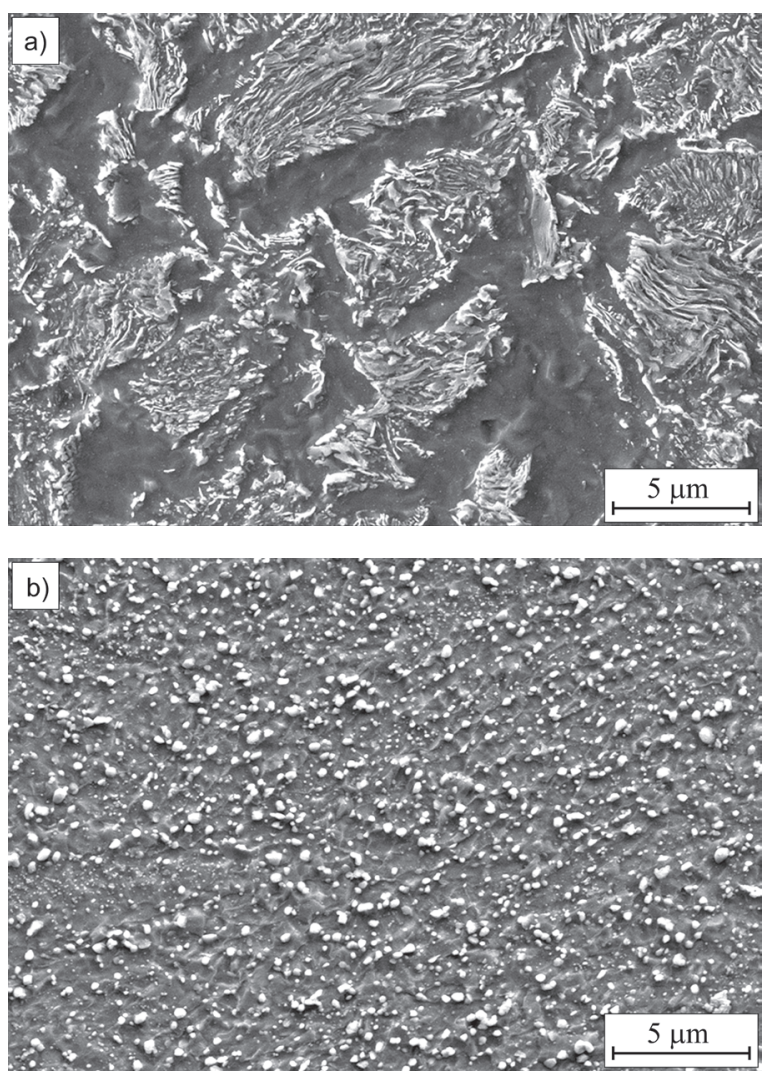

Fig. 4. SEM SE micrographs; a) as-received, and b) $45 \%$ cold strained and recrystallized $1 \mathrm{~h}$ at $600^{\circ} \mathrm{C}$

After cold straining, the appearance of carbiderich areas did not change much. As expected, the majority of deformation took place in the ferritic regions, because the yield stress of ferrite is lower than that of carbide-containing areas. Due to recrystallization, the homogeneity of the material improved significantly. The shape of cementite platelets transformed from lamellar to nodular, while the already more or less globular particles coarsened slightly, Fig. 4b. However, some areas could still be observed containing solely very fine cementite particles. These areas are former martensite and/ or bainite, while areas containing predominantly coarser particles are most likely spheroidized pearlite. A microstructure consisting of a ferritic matrix containing fine dispersed nodular cementite particles is normally representative for the quench-hardened and tempered steels. However, as shown in Fig. 4b, cold plastic straining followed by recrystallization can also produce uniformly dispersed nodular cementite. 


\subsubsection{Fracture Surfaces}

The fracture surfaces of tensile test specimens are presented in Fig. 5. It is evident that the fractures of the as-received and recrystallized specimens, Figs. $5 \mathrm{a}$ and $\mathrm{b}$, respectively, were ductile. The fracture surfaces in both conditions exhibited small dimples of fairly uniform size, though, the surface of the asreceived specimen was slightly less uniform, which is, as the lower elongation, consistent with its less homogeneous microstructure. The ductile fracture still prevailed even in the cold strained condition. However, the dimples were larger, much less uniform and some brittle fractured areas were observed. Such fracture behavior resulted in significantly lower elongations.
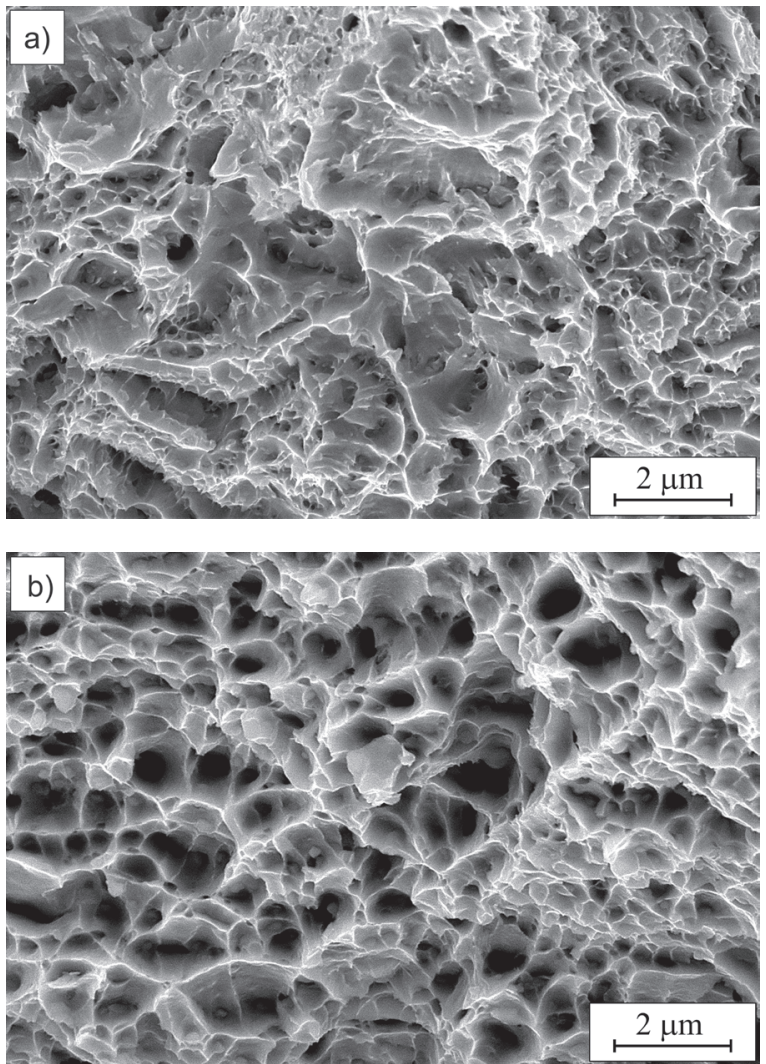

Fig. 5. The fracture surfaces of the tensile test specimens, SEM SE images; a) as-received, and b) $30 \%$ cold strained and recrystallized $1 \mathrm{~h}$ at $600{ }^{\circ} \mathrm{C}$

Compared to the tensile test specimens, the fracture surfaces of the Charpy impact test, Fig. 6, specimens were less uniform, and all of them showed the mixed fracture character. In the as-received specimen, Fig. 6a, two large cavities were observed still containing spherical particles - manganese sulfide inclusions, as the EDX analysis revealed. Similar cavities were also present in the cold strained and recrystallized specimens, Fig, 6b. The surfaces of these cavities were smooth, as is characteristic for a transcrystalline brittle fracture. The areas around the cavities were rougher, showing a more ductile behavior. Also, outside the large cavities, flat surfaces could be observed, the least of them in the recrystallized specimen. This indicates that the rupture started with a brittle fracture by the instant formation of relatively large cracks around the sulfide inclusions and continued in a partially ductile way.
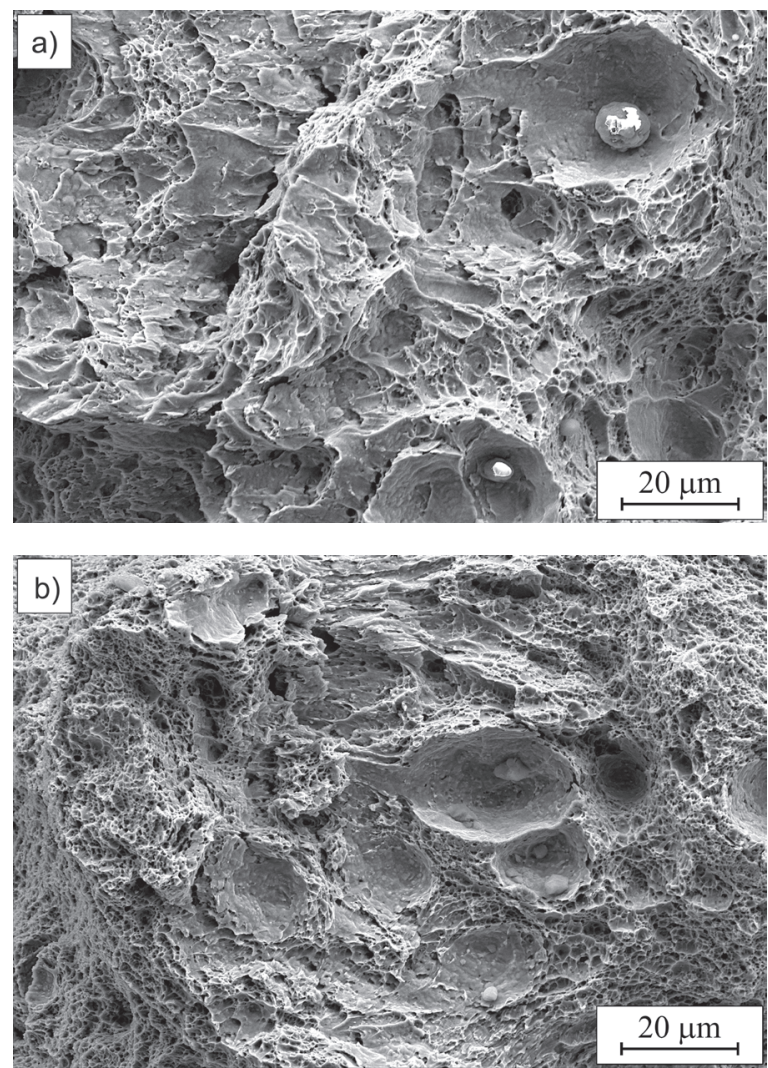

Fig. 6. Fracture surfaces of Charpy impact test specimens, SEM SE micrographs; a) as-received, and b) $45 \%$ cold strained and recrystallized $1 \mathrm{~h}$ at $600^{\circ} \mathrm{C}$

Comparing the Figs. $6 a$ and $b$, the proportion of brittle fracture seems to be slightly larger in the asreceived condition than after recrystallization.

The above observations are consistent with differences in microstructures. However, the absorbed impact energies of the as-received and recrystallized specimens were very similar. This indicates that the differences in their microstructures did not influence their impact toughness crucially - most likely because of the presence of numerous inclusions. 


\section{CONCLUSIONS}

Microstructures and mechanical properties of asreceived, cold strained and recrystallized specimens of 31Mn4+QT630 steel, cut from a TH 29-profile, were investigated to assess the possibilities of treatment and reuse of heavily strained segments of a steel arch support system. The results can be recapitulated as follows:

- Apart from elongations, the mechanical properties of as-received material corresponded to the applicable standard. Elongations were partially below the requirements for the condition +QT630. The hardness was below 250 HV 30.

- The microstructure of the as-received material was not characteristic for a QT steel. It was inhomogeneous, and contained significant fractions of proeutectoid ferrite and pearlite.

- Upon cold plastic straining, hardness increased approximately linearly with the degree of strain, approximately $2 \mathrm{HV}$ per $1 \%$ of strain. Thereby, if the original hardness is known, simple and reliable estimation of the degree of cold plastic strain is possible.

- The homogeneity of the material was improved significantly upon cold plastic straining and subsequent recrystallization. The microstructure of recrystallized specimens consisted of a ferritic matrix containing evenly dispersed globular carbide particles, which was similar to microstructures, characteristic for properly quenched and tempered carbon steels.

- By recrystallization of cold strained specimens for $1 \mathrm{~h}$ at $600{ }^{\circ} \mathrm{C}$ to $620^{\circ} \mathrm{C}$, the required combination of mechanical properties could be restored in most cases. On average, yield strength, elongation and hardness were higher and the tensile strength was lower than in the as-received condition. Impact toughness reached values over $90 \mathrm{~J}$ ISO-V, and was on average practically the same as in the asreceived condition.

- By means of an adequate single step heat treatment, the initial mechanical properties of strain-hardened steel can be recovered or even improved.

- By the implementation of a treatment protocol, consisting of determination of the degree of cold strain and a corresponding single-step heat treatment, it should be possible to increase the reuse rate of steel arch segments and thereby to decrease the expenses for new profiles significantly.

\section{ACKNOWLEDGEMENTS}

This work was supported by the coal mining company Premogovnik Velenje d.d. The sponsor had no influence on the study design, data collection, interpretation of results, and decision to submit the article for publication.

\section{REFERENCES}

[1] Potvin, Y. (2009). Strategies and tactics to control seismic risks in mines. The Journal of The Southern African Institute of Mining and Metallurgy, vol. 109, p. 177-186..

[2] Horyl, P., Šňupárek, R., Maršálek, P. Pacześniowski, K. (2017). Simulation of Laboratory Tests of Steel Arch Support. Archives of Mining Sciences, vol. 62, no. 1, p. 163-176, D0l:10.1515/ amsc-2017-0012.

[3] Kang, H. (2014). Support technologies for deep and complex roadways in underground coal mines: a review. International Journal of Coal Science \& Technology, vol 1, p. 261-277, DOI:10.1007/s40789-014-0043-0.

[4] Grodzicki, M., Rotkegel, M. (2018). The concept of modification and analysis of the strength of steel roadway supports for coal mines in the Soma Basin in Turkey. Studia Geotechnica et Mechanica, vol. 40, no. 1, p. 38-45, D0l:10.2478/sgem-20180006.

[5] Huang, W.P., Yuan, Q. Tan, Y.L. Wang, J. Liu, G.L. Qua, G.L., Li, C. (2018). An innovative support technology employing a concrete-filled steel tubular structure for a 1000-m-deep roadway in a high in situ stress field. Tunnelling and Underground Space Technology, vol. 73, p. 26-36, DOI:10.1016/j.tust.2017.11.007.

[6] Khalymendyk, I., Baryshnikov A. (2018). The mechanism of roadway deformation in conditions of laminated rocks. Journal of Sustainable Mining, vol. 17, no. 2, p. 41-47, Dol:10.1016/j. jsm.2018.03.004.

[7] Stephan, P.C.W. Bartel, R. Bauer, M., Opolony, K., Ruppel, U., Schmidt, M., Wittenberg D., Witthaus H. (2009). Roadway support systems. Junker, M. (ed.) Strata Control in In-Seam Roadways, 1st ed., VGE Verlag GmbH, Essen, p. 299 and 342.

[8] Vižintin, G., Mayer, J., Lajlar B., Vukelić Ž. (2017). Rock burst dependency on the type of steel arch support in the Velenje mine. Materiali in tehnologije/Materials and Technology, vol. 51, no. 1, p. 11-18, Dol:10.17222/mit.2016.084.

[9] Burchart-Korol, D., Fugiel, A., Czaplicka-Kolarz, K., Turek, M. (2016). Model of environmental life cycle assessment for coal mining operations. Science of the Total Environment, vol. 562, p. 61-72, Dol:10.1016/j.scitotenv.2016.03.202.

[10] Zhao, M., Chen, Q. (2013). Parameters optimization of low carbon low alloy steel annealing process. Acta Metallurgica Sinica (English Letters), vol. 26, p. 122-130, D0l:10.1007/ s40195-012-0141-1.

[11] Al-Qawabah, S.M.A., Alshabatat, N., Al-Qawabeha, U.F. (2012). Effect of annealing temperature on the microstructure, microhardness, mechanical behavior and impact toughness of low carbon steel grade 45. International Journal of 
Engineering Research and Applications, vol. 2, no. 3, p. 15501553.

[12] Kubendran Amos, P.G., Bhattacharya, A., Nestler, B., Ankit, K. (2018). Mechanisms of pearlite spheroidization: Insights from 3D phase-field simulations. Acta Materialia, vol. 161, p. 400411, D0l:10.1016/j.actamat.2018.09.043.

[13] Ji, C., Wang, L., Zhu, M. (2015). Effect of subcritical annealing temperature on microstructure and mechanical properties of SCM435 steel. Journal of Iron and Steel Research International, vol. 22, p. 1031-1036, D0I:10.1016/S1006706X(15)30108-4.

[14] Hernández-Silva, D., Morales, R.D., Cabañas-Moreno, J.G. (1992). The Spheroidization of cementite in a medium carbon steel by means of subcritical and intercritical annealing, ISIJ International, vol. 32, no. 12, p. 1297-1305, D0l:10.2355/ isijinternational.32.1297.

[15] Bhattacharya, A., Karmakar, A., Karani, A., Ghosh, M., Chakrabarti, D. (2019). Processing of ultrafine-grained steels by warm rolling and annealing. Journal of Materials Engineering and Performance, vol. 28, p. 753-768, D0l:10.1007/s11665-018-3846-0.

[16] Mugas, G.W.Q., García Sánchez, L., Criado Portal, A.J. (2015). Obtaining multiphase structure with a subcritical annealing followed by quenching in water/oil din ck55 steel. International Journal of Recent Scientific Research, vol. 6, no. 9, p. 6506-6511.

[17] Pérez, M. (2017). Impact of annealing treatments on the softening and work hardening behaviour of Jethete M152 alloy for subsequent cold forming processes. Materials Science \& Engineering: A, vol. 690, p. 303-312, D0l:10.1016/j. msea.2017.03.012.

[18] Ghiabakloo, H., Kazeminezhad, M. (2017). Rapid annealing of severely deformed low carbon steel in subcritical temperature range. Metals and Materials International, vol. 23, p. 984993, Dol:10.1007/s12540-017-6753-2.

[19] Yang, C.C., Lu, N.H. (2019). Improvement in performance of cold-drawn SCM435 alloy steel wires through optimization of intercritical annealing parameters. Sensors and Materials, vol. 31, no. 11, p. 3639-3654, D0l:10.18494/SAM.2019.2511.

[20] Yang, C.C., Lu, N.H. (2019). The inspection of spheroidized annealing on SCM435 cold-forging quality steel wires with protective atmosphere. Materials Sciences and Applications, vol. 10, no. 11 p. 677-686, Dol:10.4236/msa.2019.1011048.

[21] Yang, C.C., Lu, N.H. (2018). Optimization of intercritical annealing process parameters for SCM435 alloy steel wires by using taguchi method. Advances in Materials, vol. 7, no. 4, p. 144-152, D0I:10.11648/J.am.20180704.17.

[22] Joo, H.S., Hwang, S.K., Baek, H.M., Im, Y.T., Son, I.H., Bae, C.M. (2014). Manufacturing of medium carbon steel wires with improved spheroidization by non-circular drawing sequence. Procedia Engineering, vol. 81, p. 682-687, D0l:10.1016/j. proeng.2014.10.060.

[23] Kapoor, I., Lan, Y., Rijkenberg, A., West, G., Li, Z., Janik, V. (2020). Correlative analysis of interaction between recrystallization and precipitation during sub-critical annealing of cold-rolled low-carbon $\mathrm{V}$ and $\mathrm{Ti}-\mathrm{V}$ bearing microalloyed steels. Materials Science \& Engineering: A, vol. 785, art. ID 139381, DOI:10.1016/j.msea.2020.139381.

[24] Min, S.H., Ha, T.K. (2014). Tensile Behavior of Spheroidizing Heat Treated High Carbon Steel. International Journal of Industrial and Manufacturing Engineering, vol. 8, no. 2, p. 105-107.

[25] Yang, C.C., Liu, C.L. (2016). Improvement of the mechanical properties of 1022 carbon steel coil by using the taguch method to optimize spheroidized annealing conditions. Materials, vol. 9, no. 8, art. ID 693, D0l:10.3390/ma9080693.

[26] DIN 21530-3:2016-09. Mine Support - Part 3: Requirements. DIN Deutsches Institut für Normung e. V., Berlin.

[27] Majcherczyk, T., Malkowski, P. (2005). Strata control in underground tunnels - perspectives for development, from https://pdfs.semanticscholar.org /321f/179780de59f1c8bf02cc44fcc60e93d53551. pdf?_ga=2.102416705.1129611184.15994696372057794961.1599469637, accessed on 07-09-2020.

[28] Plesea, V., Radu, S.M. (2013). The identification and assessment of deficiencies met during the manufacture of metallic elements for sliding supports of underground excavations. Mining Revue, vol. 19, no. 3, p. 10-15.

[29] Radu, S.M., Veres, I., Plesea, V. (2016). New types of laminated profiles for the construction of sliding metallic support reinforcements. Annals of the Constantin Brancusi University Targu Jiu, Engineering Series, no. 2, p. 56-62.

[30] Kilerci, I., Culha, 0. (2018). Simulation-aided investigation of the effect of a pre-forming process on the initiation of cracks, the required forging forces and material flowlines for mining ground support clamps' manufacture using the hotforging technique. Materiali in tehnologije - Materials and Technologies, vol. 52, no. 4, p. 389-396, D0l:10.17222/ mit.2017.195.

[31] Aritan, A.E., Can, M.F. (2019). The corrosion effect on supports used in underground mining operations generated by low-rank salt-bearing coals: the Central Anatolia case. Arabian Journal of Geosciences, vol. 12, art, ID 200, D0l:10.1007/s12517019-4349-5.

[32] Janas, P., Koubova, L., Krejsa, M. (2016). Load carrying capacity of steel arch reinforcement taking into account the geometrical and physical nonlinearity. Applied Mechanics and Materials, vol. 821, p. 709-716, D0l:10.4028/www.scientific. net/AMM.821.709.

[33] DIN 50125:2016-12. Testing of Metallic Materials - Tensile Test Pieces. Beuth Verlag GmbH, Berlin.

[34] ISO 148-1:2016. Metallic Materials - Charpy Pendulum Impact Test - Part 1: Test Method. International Organization for Standardization, Geneva.

[35] Smallman, R.E., Ngan, A.H.W (2014). Modern Physical Metallurgy, $8^{\text {th }}$ ed., Butterworth-Heinemann, Oxford, p. 38587.

[36] IMS S.p.A. (2018). Special Steels: Product Catalogue, p. 212 from: http://www.ims.it/ims/ims_spa/cmscontent.nsf/Docu mentsByIDWeb/74KDY8?OpenDocument, accessed 2020-0525. 